\title{
Forgiveness in Marriage: Current Status and Future Directions
}

Frank D. Fincham
Julie Hall
Steven R. H. Beach*

\begin{abstract}
Interest in forgiveness has exploded in recent years as researchers and clinicians have begun to recognize

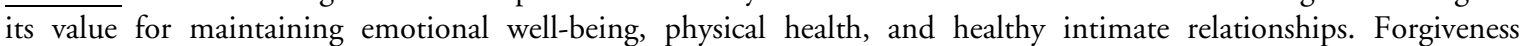
appears to be especially important in the marital relationship. This article offers an overview of forgiveness in marriage including a review of major research and clinical efforts in this area. A number of recommendations are offered for practitioners and future research directions are outlined. Marital forgiveness is seen as an exciting area for future exploration and one that is ripe with possibility.
\end{abstract}

$\underline{\text { Key Words: }}$ couple therapy, forgiveness, intimate relationships, marriage.

A happy marriage is the union of two good forgivers.--Robert Quillen

Although practitioners have long understood the importance of forgiveness in relationships, only in recent years has it become a topic of inquiry in the empirical and clinical literatures. Only five studies on forgiveness appeared prior to 1985, a number that has since increased by over $4,000 \%$ (Fincham, Jackson, \& Beach, 2005). The slow infusion of forgiveness in counseling (DiBlasio \& Proctor, 1993) may reflect an aversion to the religious origins of the construct (e.g., Rye et al., 2000) or the fact that many of the early models of forgiveness had limited utility for clinicians (McCullough \& Worthington, 1994). However, the importance of forgiveness for mental and physical health has now become widely recognized (e.g., Harris \& Thoresen, 2005; Toussaint, Williams, Musick, \& Everson, 2001). Forgiveness is also an important element in romantic relationships; the capacity to seek and grant forgiveness is seen as one of the most significant factors contributing to marital longevity and marital satisfaction (Fenell, 1993). Further, marital therapists note that forgiveness is a critical part of the healing process for major relationship transgressions such as infidelity (Gordon, Baucom, \& Snyder, 2005) as well as dealing with everyday relationship hurts (Fincham, Beach, \& Davila, 2004). This article describes the nature of forgiveness and its importance in marriage and briefly summarizes some of the major research and interventions in this area. Finally, it explores the implications of this work for practitioners and highlights future directions for the field.

\section{What Is Forgiveness?}

Scholarly definitions of forgiveness abound, but we choose to start with an exploration of lay conceptions of forgiveness as these conceptions have important implications for couple behavior and clinical work with couples. Often clinicians will find that

*Frank D. Fincham is an Eminent Scholar at the Family Institute, Sandels Building, Florida State University, Tallahassee, FL 32306-1491 (ffincham@fsu.edu). Julie Hall is an Intern in the Psychology Department, State University of New York at Buffalo, Buffalo, NY 14260 (jhasman@acsu.buffalo.edu). Steven R. H. Beach is a Professor at the Institute for Behavioral Research, Barrow Hall, University of Georgia, Athens, GA 30602-3013 (sbeach@egon.psy.uga.edu). 
clients are averse to the idea of forgiveness before any attempts to facilitate forgiveness are even underway. This is not surprising as many individuals believe that forgiveness requires one to forget about a transgression and reconcile with the offender (Kearns \& Fincham, 2004). It is also widely believed that one must accept, condone, or excuse an offense in order to forgive. Finally, some individuals associate forgiveness with feelings of weakness or being a pushover and fear that forgiving an offender permits that person to hurt them again (Kearns \& Fincham). Given these negative beliefs about forgiveness, it is easy to understand why clients might be hesitant to work toward forgiveness and why therapists might refrain from encouraging the process. Particularly in the case of egregious transgressions such as physical violence or infidelity, advocating acceptance and reconciliation can be potentially dangerous. Many clinicians and clients may also be uneasy with the idea of forgiveness because of a belief that it is a religious act, or must be approached from a religious perspective, a viewpoint shared by those scholars who view forgiveness as a "method of coping, often religious in nature" (Pargament, 1997, p. 303).

Many elements of lay conceptions of forgiveness fall in direct opposition to the way researchers have defined the construct. Further, "expert" definitions include some ideas (e.g., forgiveness as a process) not mentioned by many laypersons (Kearns $\&$ Fincham, 2004; Younger, Piferi, Jobe, \& Lawler, 2004). Although definitions of forgiveness in the research literature have varied, the field is moving closer to a consensual definition of forgiveness (Worthington, 2005). Simply put, common to most definitions of forgiveness is the idea of a change whereby one becomes less motivated to think, feel, and behave negatively (e.g., retaliate, withdraw) in regard to the offender. Forgiveness is not something to which the offender is entitled but is granted nonetheless, leading some scholars to describe it as an altruistic gift (e.g., Enright, Freedman, \& Rique, 1998; Worthington, 2001) or as the cancellation of a debt (Exline \& Baumeister, 2000). Finally, forgiveness has both intrapersonal and interpersonal elements; McCullough, Pargament, and Thoresen (2000) described forgiveness as an "intraindividual, prosocial change toward a perceived transgressor that is situated within a specific interpersonal context" (p. 9). The interpersonal context of forgiveness becomes particularly salient in marriage, as discussed later in this section.

\section{Forgiveness Distinguished From Other Constructs}

Given lay conceptions of forgiveness, which equate it to other concepts such as acceptance, it is particularly important to draw several distinctions. Forgiveness needs to be distinguished from accepting, excusing, or condoning an offense. Whereas acceptance implies that the victim changes his/her view of the offense, forgiveness does not require the transgression to be seen as anything less than it is, be this unacceptable or even reprehensible. This is one reason why Gandhi (2000) stated that "the weak can never forgive. Forgiveness is an attribute of the strong" (p. 301). Rather, an individual forgives despite the wrongful nature of the offense and the fact that the offender is not entitled to forgiveness.

Forgiveness also differs from condoning or excusing an offense as one need not believe that the behavior in question was justified or defensible. Further, forgiveness is distinct from denial (unwillingness to perceive the injury), pardon (granted only by a representative of society such as a judge), forgetting (removes awareness of offence from consciousness; to forgive is more than not thinking about the offence), and reconciliation (which restores a relationship and is therefore a dyadic process). This last point is particularly important as many laypersons (Kearns \& Fincham, 2004) and a few scholars (e.g., Hargrave \& Sells, 1997) believe that reconciliation is an important component of forgiveness. However, most scholars argue that forgiveness does not require reconciliation (e.g., Enright, 1996; Enright \& Coyle, 1998; Enright et al., 1998; Freedman, 2000). Although relationships may continue after an offense, this does not necessarily mean that the offense is forgiven. Conversely, the decision to terminate the relationship does not prevent the partners from forgiving one another. However, it is worth noting that forgiveness may make reconciliation more likely (Hall \& Fincham, 2006).

\section{Forgiveness as an Intentional Process}

Forgiveness involves change (McCullough \& Root, 2005; McCullough, Fincham, \& Tsang, 2003) and is best viewed as a process rather than a specific act (e.g., Enright \& Fitzgibbons, 2000; Fincham, 2000). Thus, forgiveness lends itself nicely to stage/phase models that conceptualize the construct as a transformation that occurs over time. Several phase models have been used to inform forgiveness interventions 
for close relationships (Coleman, 1998; Enright \& Fitzgibbons; Gordon, Baucom, \& Snyder, 2000). The majority of models of forgiveness specify that it is an intentional process driven by a deliberate decision to forgive (Fincham; Enright, 1996; see Worthington, 2005, for a review).

\section{Multidimensional in Nature}

Although some of the early definitions of forgiveness were unidimensional, focusing on a decrease in negativity (i.e., retaliation or withdrawal, labeled unforgiveness) toward the offender, recent studies of marital forgiveness have challenged this assumption and emphasized an additional positive or benevolence dimension that involves acting with goodwill toward the marital partner (Fincham, 2000; Fincham $\&$ Beach, 2002; Fincham et al., 2004). Interestingly, laypersons tend to view benevolence or other positive features as more representative of forgiveness than a decrease in negativity (Kearns \& Fincham, 2004). Indeed, forgiveness may be unidimensional in noncontinuing relationships (Worthington, 2005) but appears to have both positive (benevolence) and negative (unforgiveness) elements in close relationships that continue.

Before turning to the relational context, it is helpful to consider the question of who benefits from forgiveness. One view is that the forgiver is the primary beneficiary; from this perspective, it is tempting to conclude that the cessation of negative affect, cognitions, and behavior toward the offender constitutes forgiveness (e.g., Gordon \& Baucom, 1998). A second viewpoint emphasizes the offender as the primary beneficiary as he/she receives an undeserved gift (Enright et al., 1998) and is released from an obligation (Exline \& Baumeister, 2000). This perspective tends to emphasize the positive dimension of forgiveness and in its most extreme form views positive interaction or reconciliation, or both, with an offender as a prerequisite for forgiving (e.g., Hargrave, 1994; Pollard, Anderson, Anderson, \& Jennings, 1998). However, little is known about the perspective of the offender (McCullough et al., 2000) and how the relationship between the victim and the offender may influence forgiveness. In any event, spouses view of who is the primary beneficiary of forgiveness is likely to have important implications for how they, among other things, interpret attempts to encourage forgiveness (Butler, Dahlin, $\&$ Fife, 2002).

\section{Relational Context}

As noted earlier, forgiveness occurs within a relational context (McCullough et al., 2000), and the nature of the relationship (e.g., closeness, quality) is related to forgiveness (see next section). Many view forgiveness as an interpersonal transaction and thus focus on how it is manifest in dyadic interactions (e.g., Fincham, 2000; Worthington, 1998). Forgiveness can be observed in exchanges between the offender and the victim and how these exchanges unfold is likely to influence the forgiveness process. For example, it is well established that an apology from the transgressor facilitates the forgiveness process (e.g., McCullough et al., 1998). Thus, forgiveness must be explored within context by researchers and clinicians alike.

We turn now to consideration of forgiveness within one particular relational context, marriage ${ }^{1}$. We highlight some of the major research and clinical efforts in this area and attempt to integrate these efforts when possible.

\section{The Role of Forgiveness in Marriage: Research and Intervention}

Many researchers and clinicians believe that forgiveness is the cornerstone of a successful marriage (e.g., Worthington, 1994), a view that, as noted earlier, is often shared by both spouses (Fenell, 1993). Although both attempts to integrate forgiveness into broader theories of marriage and to develop theoretical perspectives on forgiveness in marriage are scarce, it is widely believed that forgiveness can help couples to deal with existing difficulties and prevent the emergence of future problems (e.g., Worthington \& DiBlasio, 1990). Transgressions within marriage may be especially painful when they are seen to violate the sanctity of the marital bond, thus making forgiveness particularly challenging but critical to sustaining the relationship (Mahoney, Rye, \& Pargament, 2005). But when is forgiveness necessary in a marriage? After an argument? A broken

\footnotetext{
${ }^{1}$ This article is limited to consideration of forgiveness in marriage. However, there is no reason to believe that forgiveness processes differ in committed heterosexual relationships that are not legally recognized (e.g., cohabiting relationships) or in gay and lesbian relationships.
} 
promise? Gordon et al. (2000) argued that forgiveness is important in situations where marital assumptions or relationship standards have been breached. Similarly, in contextual family therapy (e.g., Boszormenyi-Nagy \& Krasner, 1986), Hargrave and Sells (1997) proposed that forgiveness is important when transgressions violate partners' relational ethics and sense of justice in the marriage. Unfortunately, assumptions and standards of marital relationships are threatened all too often such that forgiveness may be a regular component of marriage. Given its importance and pervasiveness in marriage, forgiveness has been explored in regard to several other aspects of marriage.

In the absence of an integrative theory of forgiveness in marriage, available research tends to be somewhat fragmented. Given the centrality of relationship satisfaction in the broader marital literature, it is not surprising that substantial attention has been given to the relationship between marital satisfaction and forgiveness. Because investigation of marital satisfaction has recently expanded to include consideration of ambivalence (Fincham \& Linfield, 1997), forgiveness has also been investigated in relation to this construct. Similarly, two constructs widely believed to influence marital satisfaction, couple conflict and attributions or explanations for spousal behavior, have also been investigated by forgiveness researchers. Finally, two constructs believed to be important for forgiveness, the degree of commitment in the relationship between offender and victim and empathy experienced by the victim toward the offender, have also been investigated. We now briefly highlight research on these topics (see Fincham, Hall, \& Beach, 2005, for a review).

\section{Satisfaction}

Several studies have documented a positive association between relationship satisfaction and forgiveness (e.g., Fincham, 2000; Gordon \& Baucom, 2003; Kachadourian, Fincham, \& Davila, 2004; Paleari, Regalia, \& Fincham, 2003). Although robust, the mechanism underlying the link between satisfaction and forgiveness remains unclear. McCullough et al. (1998) proposed several possible mechanisms, including a greater likelihood of confession and apology in satisfied intimate relationships, leading to more forgiveness. Despite little longitudinal or experimental work in this area, it appears that the association between forgiveness and relationship quality may be bidirectional. There is emerging evidence that marital quality predicts forgiveness (Paleari et al., 2003), as well as data that trait forgiveness predicts later marital satisfaction (Vaughan, 2001). It also appears that forgiveness-based interventions may boost marital satisfaction (Alvaro, 2001; Sells, Giordano, \& King, 2002).

\section{Ambivalence}

Just as there are positive and negative dimensions of forgiveness, marital partners may feel both positively and negatively toward one another (Fincham \& Beach, 2006; Fincham \& Linfield, 1997), and this ambivalence influences forgiveness (Kachadourian, Fincham, \& Davila, 2005). Specifically, transgressions may serve to prime the negative components of this ambivalence and, when coupled with rumination about the offense, appear to result in decreased forgiveness of one's partner (Kachadourian et al., 2005). This is particularly dangerous for couples because ambivalence is also associated with an increased propensity to respond in an extreme manner, leading to the potential for generation of new relationship transgressions. In the context of marital interventions to promote forgiveness, it may behoove clinicians to counter ambivalence by activating positive feelings, identifying areas of strength in the relationship, and building on positive beliefs about the offending partner.

\section{Conflict}

Forgiveness is also related to conflict resolution among married couples, independently of relationship satisfaction. Fincham et al. (2004) found that retaliation and avoidance (i.e., negative dimensions of forgiveness) among husbands and a lack of benevolence (i.e., positive dimension of forgiveness) among wives were linked to ineffective conflict resolution. Although the causal direction of these associations is unclear, Fincham et al. suggested that unresolved transgressions may spillover into future conflicts and, in turn, impede their resolution, thereby putting the couple at risk for developing the negative cycle of interaction that characterizes distressed marriages. This would provide a mechanism that links forgiveness and relationship satisfaction and is further supported by the finding that forgiveness predicts behavioral responses to partner transgressions (Fincham, 2000). 


\section{Attributions}

Within the general forgiveness literature, a number of studies have demonstrated that attributions or explanations for the offending behavior predict forgiveness as benign attributions are related to greater levels of forgiveness than are nonbenign or conflictpromoting attributions (e.g., Boon \& Sulsky, 1997; Bradfield \& Aquino, 1999; Weiner, Graham, Peter, \& Zmuidinas, 1991). Among married couples, Fincham, Paleari, and Regalia (2002) found that benign attributions predicted forgiveness both directly and indirectly through lessening negative emotional reactions to the transgression and increasing empathy toward the transgressing spouse. Moreover, forgiveness mediates the association between attributions and behavior toward one's spouse independently of marital satisfaction (Fincham, 2000).

This association between attributions and forgiveness has been used to inform forgiveness interventions as scholars agree that changing one's view of the offender and his/her behavior may enhance forgiveness (Fincham, 2000; Freedman, 2000; Gordon et al., 2000). Indeed, explicit attention to attribution retraining has been incorporated into one clinical intervention designed to facilitate forgiveness (Al-Mabuk, Dedrick, \& Vanderah, 1998). However, it is worth noting that attention to changing attributions may be more important for women than men; it appears that responsibility attributions are more predictive of forgiveness for wives than for husbands (Fincham et al., 2002). This is consistent with a larger body of evidence that supports the strong association between attributions and behavior among women (see Fincham, 2001).

\section{Commitment}

Because both commitment and forgiveness are believed to promote pro-relationship motives, it has been postulated that the two constructs are positively related. Consistent with this hypothesis, McCullough et al. (1998) found that partners who reported greater satisfaction and commitment also expressed higher levels of forgiveness within their romantic relationships. Although the causal relationship between the constructs is somewhat uncertain, Finkel, Rusbult, Kumashiro, and Hannon (2002) provided experimental data suggesting that greater commitment facilitates interpersonal forgiveness. These authors argued that the commitment- forgiveness association is driven by the intent to persist as highly committed individuals may be more motivated to forgive simply because they intend to remain in their current relationship. However, Tsang, McCullough, and Fincham (2006) offered longitudinal evidence that forgiveness promotes increases in commitment, although they also found limited evidence that effects also ran in the opposite direction. Finally, there is evidence that benign attributions may mediate the association between commitment and forgiveness as committed individuals tend to interpret their partners' betrayals in a more benevolent manner, which may thereby promote forgiveness. The association between commitment and forgiveness is especially relevant to practitioners working with couples as therapists might aim to highlight or enhance commitment in an effort to encourage forgiveness. Similarly, when partners are ambivalent about the relationship and the intent to persist is wavering, forgiveness may be a more difficult therapeutic process.

\section{Empathy}

Empathy is a relationship construct that appears to play an important role in the forgiveness process (e.g., McCullough et al., 1998) and, therefore, has been incorporated in forgiveness interventions. Attention to enhancing empathy may be particularly important for men; Fincham et al. (2002) found that empathy was a better predictor of forgiveness in husbands than among wives, potentially because empathic behavior tends to be less common for men in relationships and therefore more influential.

\section{Marital Forgiveness Interventions}

Although forgiveness unfolds naturally in many marriages, at times couples may seek the help of a professional in the aftermath of painful transgressions. Several interventions have been shown to increase forgiveness in romantic relationships (Gordon, Baucom, \& Snyder, 2004; Rye \& Pargament, 2002; Sells et al., 2002), and various models of forgiveness have been used to develop these interventions. Stage/ phase models (Hargrave \& Sells, 1997; McCullough, Worthington, \& Rachal, 1997) lend themselves particularly well to therapy, provided clinicians recognize that these stages may overlap or occur out of order (Enright \& Fitzgibbons, 2000; Gordon et al., 2000). Enright's (1996) model of 
forgiveness has received empirical support and views forgiveness as a journey through four phases (Enright \& Fitzgibbons). The first phase, termed the "uncovering phase," focuses on exploring the hurt that the victim has experienced. This is followed by a "decision phase" in which the nature of forgiveness is discussed, and the individual commits himself/herself to trying to forgive the offender. The third "work phase" shifts the focus to the transgressor in an effort to gain insight and understanding. Finally, during the "deepening phase," the victim moves toward resolution, becoming aware that he or she is not alone, has him or herself been the recipient of others' forgiveness, and finds meaning and purpose in the forgiveness process.

Coleman (1998) and Gordon et al. (2000) have offered similar models specific to marital forgiveness. Gordon et al.'s (2000) three-stage model of marital forgiveness posits the victim must cope with the impact of the offense, find meaning for the transgression, and then move forward with a new set of relationship beliefs. This model appears most appropriate for transgressions, which Gordon et al. (2000) termed "interpersonal traumas," such as affairs. An intervention using this model has shown preliminary success in helping couples struggling with infidelity. Couples participating in the intervention showed decreased emotional and marital distress and increased forgiveness of the infidelity (Gordon et al., 2004).

Marital group therapy (Sells et al., 2002) and marital enrichment interventions (Burchard et al., 2003; Ripley \& Worthington, 2002) are among the types of treatment that have been used to facilitate forgiveness among couples. Rye and Pargament (2002) have extended these intervention efforts to individuals in dating relationships with success in facilitating forgiveness. At the level of prevention, some marital education programs, such as the Prevention and Relationship Enhancement Program (PREP; Stanley, Markman, \& Blumberg, 2001), include a section on forgiveness. The use of various intervention modalities to encourage forgiveness in close relationships is an important area for future exploration, especially when one conceptualizes unforgiveness as a public health problem. Fincham and Beach (2002) described different ways to address this problem, including the potential use of an Internet-based forgiveness intervention (see Braithwaite \& Fincham, 2006), and Fincham and Kashdan (2004) provided a preventive framework for facilitating forgiveness at the individual, group, and community levels.
Critique. The most striking feature of the intervention literature is the large number of interventions available relative to the very small number that have received any empirical evaluation. Moreover, scholars have built forgiveness models for intervention "without demonstrating empirically that forgiveness in fact unfolds in the hypothesized manner" (Malcolm \& Greenberg, 2000, p. 184). Importantly, the majority of interventions have focused on facilitating forgiveness by increasing empathy for the offender. Increased empathy may have a direct effect on retaliatory impulses by making the transgressor more understandable. Given the likely divergence of influences on the positive and negative dimensions of forgiveness, this oversight seems striking and may be critical for long-term outcomes with married partners.

Why is this the case? According to Fincham and Beach (1999), in destructive marital interactions, couples commonly switch from the largely cooperative goals they profess on a day-to-day basis to emergent goals that are adversarial in nature. An emergent goal is a goal that arises during an interaction and usually derails the original path of the interaction by allowing a corrosive process to preempt the original, more positive couple process. For example, rather than focus on generating a solution to the problem at hand, an emergent goal can lock couples in a destructive pattern of escalation where they find themselves focused on winning an argument with their partner-or at least not losing the argument. In the context of past partner offenses, such emergent goals may lead to previously forgiven transgressions being used as ammunition in the escalating battle. Because of the power of emergent goals to disrupt marital interaction, communication skills and empathy for the partner may not be enough to ensure translation of partner forgiveness into a dyadic process that is helpful to the couple. In particular, if partners have been successful in reducing retaliatory or avoidance goals, this does not necessarily mean that retaliatory goals will be absent during conflict. It may be that positive or benevolence motives are a better, or perhaps just an additional, protection against the reemergence of retaliatory motives during conflict. Likewise, it may be that positive motives are necessary for optimal conflict resolution in a dyadic context. For example, a focus on showing love to one's partner may provide greater protection against the reemergence of retaliation than does a focus on no longer avoiding contact with one's 
partner. Likewise, this focus may facilitate listening attentively rather than thinking of rebuttals to partner comments.

The Fincham and Beach (1999) analytic framework suggests that current programs for facilitating forgiveness may not provide a complete answer to marital breakdown or relationship reconciliation even if they are relatively effective in promoting a reduction in retaliatory motives in the relatively calm, nonconflictual setting of the forgiveness group. If this is the case, current forgiveness interventions may prove to be of short-lived value with regard to marital relationship outcomes and so may never fulfill their promise within the marital context. The key to enhanced longer term outcomes for marital forgiveness programs, therefore, is to find an intervention that help partners recognize and respond effectively to their own emergent retaliatory goals. To be maximally effective, such an intervention should have three characteristics. First, it should be one that readily occurs to the couple. Second, it should require minimal reasoning. Finally, it should have a calming effect on both parties.

One possibility is to build on current forgiveness programs by adding components designed to promote the positive or benevolence dimension of forgiveness. First, an effective intervention might focus on making the intellectual case for benevolence toward the partner (e.g., the benefits that accrue from one's partner doing well). This could set the stage for an emotional argument for benevolence by providing opportunities for positive basking, supporting one's positive self view, providing an opportunity for personal spiritual growth. In turn, the emotional argument might set the stage for exploring possible benefits of regular activities to express benevolence or to cognitively rehearse benevolent intentions toward one's partner. Such an argument speaks to the "better nature" of the person and appeals to their desire to be beneficent to others. Adding training in the positive dimension of forgiveness to current forgiveness interventions can also be seen as combining forgiveness interventions with motivational interviewing, a procedure that helps clients overcome the ambivalence that prevents them from making positive changes in their lives (Miller \& Rollnick, 2002).

Future interventions must also make greater efforts to incorporate relationship dynamics and use interactions between the partners to promote forgiveness. In the spirit of exploring the clinical future of marital forgiveness, we now offer several suggestions for practitioners interested in helping couples achieve forgiveness; we also identify the various ways that forgiveness may manifest in marital counseling.

\section{Recommendations for Practitioners}

\section{Psychoeducation Is Critical}

As highlighted at the beginning of this paper, lay conceptions of forgiveness differ greatly from research and clinical definitions of this construct. Thus, it is extremely important to explore client perceptions of forgiveness before attempting any explicit intervention; preconceived ideas about forgiveness may prevent clients from being open to forgiveness and thus interfere with efforts to help these individuals. For instance, if a spouse believes that in order to forgive, they must literally forget the transgression, and thereby place themselves at risk of future harm, they may be understandably reluctant to forgive. Similarly, an individual may be unwilling to forgive a partner because of a fear of being viewed as weak. Therefore, it is important to know how people think about forgiveness in order to address any negative notions that they may have about forgiveness. Any misconceptions should be corrected and the potential positive effects of forgiveness highlighted. Simply educating clients about forgiveness may assuage many of their concerns (e.g., Enright, Gassin, \& Wu, 1992) and instill a sense of hope. To its credit, the PREP takes pains to clarify the nature of forgiveness before outlining steps that can be taken to achieve forgiveness. In sum, lay conceptions have important implications for working with couples as understanding these conceptions can help inform psychoeducational and therapeutic work.

\section{Forgiveness Takes Time}

As noted earlier, because forgiveness involves change, it is best viewed as a process that takes place over time. An important implication is that forgiveness is not achieved immediately, a circumstance that can lead to problems when the offending spouse takes a partner's statement of forgiveness ("I forgive you") literally rather than as a promissory note ("I 
am trying to forgive you"). Thus, when hurt feelings regarding a transgression arise after a statement of forgiveness, the offending partner may experience confusion or anger if they believe that the matter had been previously resolved; in the normal course of events, the statement "I forgive you" is more likely to occur than the statement "I want to try and forgive you." The temptation to equate forgiveness with a specific act at a specific point in time (usually now) is strong. Accordingly, both therapists and clients need to be mindful of the temporal dimension of forgiveness.

\section{Different Forms of Forgiveness Matter}

It is also important for practitioners to be aware of the different forms of forgiveness that may manifest in therapy. For instance, Baumeister, Exline, and Sommer (1998) distinguished between intrapsychic states and interpersonal acts in considering different forms of forgiveness. Silent forgiveness occurs when one has overcome anger and resentment toward the offender but fails to demonstrate this in one's behavior. Conversely, hollow forgiveness involves the outward expression of forgiveness while still holding onto anger and resentment. Total or genuine forgiveness in their scheme requires both intrapsychic and interpersonal change. Fincham, Hall et al. (2005) also distinguished between different forms of forgiveness, drawing upon the positive and negative dimensions of forgiveness discussed earlier. Ambivalent forgiveness exists when the forgiver experiences both positive and negative sentiment toward the offender. In contrast, low levels of positive and negative sentiment characterize detached forgiveness. Complete forgiveness involves low levels of negative sentiment and high levels of positive sentiment toward the offender.

Although it does not result in forms of forgiveness of the sort outlined above, we might also use the distinction between conscious, explicit cognitive processes and nonconscious, implicit cognitive processes (e.g., Shiffrin \& Schneider, 1977) to understand forgiveness. The current focus on deliberate and effortful judgments of forgiveness may overlook aspects of forgiveness that occur outside of conscious awareness. Clinicians see this illustrated in therapy when a spouse says and believes that he or she has forgiven their partner (i.e., explicit forgiveness), only to discover resentment or a desire for revenge is instigated by the slightest cue during interaction with their partner. Thus, if we are to understand how forgiveness in marriage influences marital interaction, we also need to explore forgiveness at an implicit, nonconscious level. In particular, the prevailing focus on forgiveness as a voluntary and intentional act may need to be supplemented by a focus on forgiveness as an implicit readiness to respond.

\section{Dangers in Communicating Forgiveness}

Communication of forgiveness may lead to harm when it is unskillfully or poorly communicated. Even forgiveness that is offered in a genuine manner may be seen by the partner as a put down, a form of retaliation, or a humiliation if it is unskillfully executed. Second, statements of forgiveness may be intentionally abused. They can be used strategically to convey contempt, engage in one-upmanship, and the like. Likewise, verbal statements of forgiveness may not reflect true feelings. Such statements of forgiveness without accompanying internal changes have been labeled hollow forgiveness (Baumeister et al., 1998). Third, it is easy to confuse forgiveness with a specific statement of forgiveness (e.g., Hargrave \& Sells, 1997; Baumeister et al.). As noted earlier, the words "I forgive you" often signal the beginning of a process for the speaker (of trying to forgive the transgression) but tend to be seen as the end of the matter by the offending partner-who is also likely to be only too willing to put the transgression in the past and act as if it never happened. The offending partner is therefore likely to be puzzled, annoyed, or angry when incompletely resolved feelings of resentment about the harm-doing intrude upon subsequent discourse or behavior in the relationship.

Kelley (1998) was among the first to recognize the importance of exploring how forgiveness is expressed between individuals in daily interactions. In addition to direct and indirect strategies of communicating forgiveness, Kelley found that some victims expressed forgiveness conditionally, only granting it with certain stipulations. Although these various communication techniques capture the general expression of forgiveness, research has yet to explore forgiveness transactions specifically within the context of marriage. Given the opportunity of the clinician to witness the communication of marital forgiveness from the "front lines," it may become apparent that certain ways of expressing forgiveness are more adaptive and associated with healthy relationships. Likewise, some efforts at communicating 
forgiveness to one's spouse may backfire and further exacerbate the problem. Thus, it is important for researchers and practitioners alike to explore how forgiveness is expressed between partners.

\section{Perpetrators and Victims Have Different Perspectives}

Finally, a difference exists in perspectives between the perpetrator and the victim of harm doing (e.g., Kearns \& Fincham, 2005; Stillwell \& Baumeister, 1997) in that each encodes and recalls harm-doing events in self-serving ways. Specifically, victims tend to overlook details that facilitate forgiving and embellish their memories with details that make forgiving more difficult, whereas transgressor biases embellish details, such as extenuating circumstances, that facilitate forgiving. In the usual course of events, the victim spouse has to cancel a debt that is bigger than one acknowledged by transgressor spouse. Thus, the transgressor spouse may see their partner's reaction to the transgression as overblown and itself a wrongdoing. Should he or she act accordingly, the victim partner might then feel doubly wronged and the couple could end up engaging in a chain of escalating negative interaction. Although a danger, such escalation is not necessarily inevitable.

\section{Context Is Important}

In this section, we highlight the need to move beyond focusing on forgiveness of isolated transgressions toward a broader perspective that considers the patterns of offenses and forgiveness within marriage, as well as the distribution of marital power. Given the rich history of transgressions that most marital partners share, it is important to move beyond single offenses as each transgression is embedded in a complex relational story. For example, one cannot help a wife move toward forgiveness of her husband's onetime infidelity in the same manner that one would treat a couple where the husband had a history of multiple transgressions of this kind. Thus, clinicians need to consider how the transgressional history of a relationship influences the forgiveness of subsequent offenses within that relationship, particularly because the avoidance and retaliation that characterize unforgiveness of one transgression may spillover into subsequent interactions. Fincham, Hall et al. (2005) pointed out that chronic transgressions, such as longstanding patterns of emotional neglect, must also be considered. Worthington (1994) captured this consideration well in his observation that "The calluses on the soul may be thick and hard after years of hurting without confession, repentance, or forgiveness" (p. 167). How do spouses forgive one another for hurts that are endured day after day? Such questions cannot be answered by examining forgiveness for specific offenses without the practitioner considering the patterns of wrongdoing in the marriage. This entails considering not only major transgressions but also fairly minor offenses. When looking at forgiveness in nondistressed, longterm marriages, researchers are more likely to encounter minor transgressions than major offenses such as infidelity or physical abuse. By considering offenses within the broader context of the marital relationship, one can better understand the needs of each unique individual couple.

Finally, the degree to which power is unequally distributed in the relationship is important because power differences are likely to influence forgiveness both indirectly, through attributed responsibility (e.g., the acts of more powerful persons are more likely to be seen as expressions of their will and hence more culpable; Heider, 1958), and also directly. Indeed, we conceptualize the context in which forgiving arises in terms of power as, by definition, when a spouse harms their partner, they exert power over the partner. Retaliation and revenge can thus be seen as a means, whereby the partner reasserts his or her power and status, and abstention from retaliation/revenge can be seen as an acknowledgment of the spouse's superior power in inflicting the harm. From this perspective, we hypothesize that where a clear power imbalance exists in a relationship, the more powerful partner is likely to find it harder to forgive. Forgiving is more difficult for them because their power makes revenge particularly viable and foregoing its use requires relinquishing, at least temporarily, their superior power. Conversely, the less powerful partner is likely to find it easier to forgive. Because of their power, revenge is less viable (and defeated revenge would only affirm their lower power), and the power implications of forgiving do not require adoption of a power role, however fleetingly, that is inconsistent with their usual power/status in the relationship. If this analysis is correct-and assuming marriages in Western culture still accord men greater power than women-one would expect wives to be more forgiving of their husbands than vice versa. Stated differently, one 
might predict husband forgiveness as being more consequential for the relationship.

Although the issue of gender differences has not received much attention in the marital literature on forgiveness, it appears that gender differences do emerge in about half of the studies that examined them. When they emerge, women are usually found to be more forgiving than men (e.g., Karremans, Van Lange, Ouwerkerk, \& Kluwer, 2003; Study 4), a pattern consistent with our analysis and with gender related power differentials in society.

\section{Future Directions}

Having considered the nature of forgiveness and its significance in marriage, as well as highlighting research and clinical work in this area and offering practical recommendations, we now look toward the future of the marital forgiveness field. Several exciting areas for future exploration are highlighted, including the importance of seeking forgiveness, self-forgiveness, and the role of the sacred in marital forgiveness.

\section{Seeking Forgiveness}

Despite intentions to enhance marriages via forgiveness, many of our efforts thus far may have been misplaced. Much emphasis has been placed upon the process by which one grants forgiveness to a spouse, and although such forgiveness may be linked to marital satisfaction, seeking forgiveness may be even more important to a good marriage (Worthington, 1994). That is, rather than pointing fingers in an effort to identify which partner is in the wrong, humbling oneself before one's partner and confessing to any shortcomings may go a long ways toward strengthening a marriage in the wake of transgressions. In an illustration of his clinical work with couples, Worthington described a forgiveness session where partners make themselves vulnerable by confessing how they have hurt one another and notes the healing effect of mutual confession and forgiveness. In contrast to the growing body of literature on granting forgiveness in marriage, little research and clinical work has focused on the methods by which partners seek forgiveness, how this impacts the relationship, and the effect it has on the other spouse. Thus, this represents an area pregnant with possibility. The fact that the granting of forgiveness is linked to confessed wrongdoing (e.g., Weiner et al., 1991) and to the offering of an apology (e.g., Obuchi, Kameda, \& Agarie, 1989) in the broader literature on forgiveness augurs well for its investigation in research on marital forgiveness.

\section{Self-Forgiveness}

Another topic that has been largely overlooked in the general forgiveness literature, and particularly in the marital forgiveness literature, is self-forgiveness. Although forgiveness of the self may seem unimportant in a dyadic context, it likely plays an important role in maintaining connectedness between partners in the aftermath of marital transgressions. Selfforgiveness is conceptualized as a set of motivational changes, whereby one becomes decreasingly motivated to avoid stimuli associated with the offense (e.g., the victim), decreasingly motivated to retaliate against the self (e.g., punish the self, engage in selfdestructive behaviors), and increasingly motivated to act benevolently toward the self (Hall \& Fincham, 2005). Self-forgiveness plays an interesting role in marriage as spouses must frequently deal with the fact that they have behaved in a way that was hurtful to their partner. Just as interpersonal unforgiveness may drive a wedge between partners, so might unforgiveness of the self keep partners estranged, as the perpetrator withdraws from his/her partner and becomes consumed by guilt and self-destructive thoughts. Self-forgiveness also occurs in an interpersonal context; thus, the victimized spouse's behavior may play an important part in facilitating the perpetrator's self-forgiveness (Hall \& Fincham). In this respect, the interplay between self-forgiveness, forgiveness by the partner, and marriage has yet to be explored. As self-forgiveness receives more attention, it will be important to focus on the boundary and contextual factors that determine when self-forgiveness is essential in allowing the relationship to recover from a transgression, when it is useful in recovery of positive affect for the self, and when it may be detrimental to the relationship.

\section{Forgiveness and the Sacred}

Although the religious undertones of forgiveness have been off-putting to some researchers and clinicians, several clinical interventions, which infuse forgiveness and spirituality have been developed (e.g., 
Rye \& Pargament, 2002). Further, many couples consider their religious beliefs to be an important component of their marriage (Blumel, 1992; Jenkins, 1992; Mahoney et al., 1999). Thus, it remains important for the field to continue to explore the interplay between faith and forgiveness in the context of marriage. One exciting new line of research with great potential in this area considers the importance of sanctification of marriage and how it relates to forgiveness (Mahoney et al., 1999; Mahoney et al., 2005). Sanctification of marriage refers to the belief that one's marriage has spiritual character and significance (Mahoney et al., 1999). This may be represented by the view that marriage has spiritual qualities or by experiencing marriage as a manifestation of God, or both. When couples view marriage as something sacred, transgressions committed within the relationship may signify a form of desecration-a violation that threatens the sanctity of the marital bond and the standards that accompany this bond. Thus, these transgressions may be more difficult to forgive than those without a sacred component (Mahoney et al., 1999). Conversely, if partner forgiveness is viewed as a manifestation of spirituality this may facilitate forgiveness. This suggests that spouse's spiritual beliefs and their relation to marriage should be carefully explored. It will be important for future research and clinical work to consider methods for promoting forgiveness when transgressions threaten the sanctification of marriage.

\section{Conclusions}

A great deal of ground has been covered in this article and the terrain shared with the reader has been quite diverse. Clearly, work on forgiveness in marriage is in its infancy. William James described the world of the infant as blooming and buzzing, and this certainly seems to characterize the current status of marital forgiveness research (James, 1890). But is it, as James also said of the infant's world, confused? Certainly, there are hints of confusion (e.g., some researchers still equate the absence of retaliation as forgiveness), and our attempt to avoid adding to any confusion led us to begin this paper by considering in some detail the nature of forgiveness. Having clarified the essential features of the construct, we then went on to review and critique forgiveness research and marital forgiveness interventions. From this exercise emerged a number of recommendations for practitioners and the identification of future research directions.

It remains to note what is likely by now quite obvious. The biggest challenge facing the field is the need to integrate theory, research, and practice (e.g., McCullough \& Worthington, 1994). As Pargament, McCullough, and Thoresen (2000) noted in their landmark book entitled Forgiveness, "Until recently, practitioners have had to work largely from intuition in their efforts to understand, evaluate, and intervene in this process in the context of clinical practice" (p. 315). In more concrete terms, the field needs therapeutic tools and techniques informed by empirically sound theory and research, to facilitate forgiveness in close relationships. Gordon and colleagues (Gordon \& Baucom, 1998, 1999, 2003; Gordon et al., 2000, 2004) have set the precedent for this process in terms of marital forgiveness, integrating research and theory with their clinical experiences in working with couples. However, there is a need for more work like this, and the process will be expedited to the extent that researchers and practitioners work together to develop and validate marital forgiveness interventions. It is our hope that this paper will facilitate this process by stirring research and clinical interest in marital forgiveness.

\section{References}

Al-Mabuk, R. H., Dedrick, C. V. L., \& Vanderah, K. M. (1998). Attribution retraining in forgiveness therapy. Journal of Family Psychotherapy, 9(1), 11-30.

Alvaro, J. A. (2001). An interpersonal forgiveness and reconciliation intervention: The effect on marital intimacy. Dissertation Abstracts International, 62(1608), 3-B.

Baumeister, R. F., Exline, J. J., \& Sommer, K. L. (1998). The victim role, grudge theory, and two dimensions of forgiveness. In E. L. Worthington (Ed.), Dimensions of forgiveness: Psychological research and theological perspectives (pp. 79-106). Philadelphia: Templeton Press.

Blumel, S. R. (1992). Explaining marital success and failure. In S. J. Bahr (Ed.), Family research: A sixty-year review, 1930-1990 (Vol. 2, pp. 1-114). New York: Lexington Books.

Boon, S. D., \& Sulsky, L. M. (1997). Attributions of blame and forgiveness in romantic relationships: A policy-capturing study. Journal of Social Behavior and Personality, 12(1), 19-44.

Boszormenyi-Nagy, I., \& Krasner, B. (1986). Between give and take: A clinical guide to contextual therapy. New York: Brunner/Mazel.

Bradfield, M., \& Aquino, K. (1999). The effects of blame attributions and offender likeableness on forgiveness and revenge in the workplace. Journal of Management, 25, 607.

Braithwaite, S. R., \& Fincham, F. D. (2006). ePREP: Computer based prevention of relationship dysfunction, depression, and anxiety. Manuscript submitted for publication. 
Burchard, G. A., Yarhouse, M. A., Kilian, M. K., Worthington, E. L., Jr., Berry, J. W., \& Canter, D. E. (2003). A study of two marital enrichment programs and couples' quality of life. Journal of Psychology and Theology, 31, 240-252.

Butler, M. H., Dahlin, S. K., \& Fife, S. T. (2002). 'Languaging' factors affecting clients' acceptance of forgiveness intervention in marital therapy. Journal of Marital and Family Therapy, 28, 285-298.

Coleman, P. W. (1998). The process of forgiveness in marriage and the family. In R. D. Enright \& J. North (Eds.), Exploring forgiveness (pp. 75-94). Madison: University of Wisconsin Press.

DiBlasio, F. A., \& Proctor, J. H. (1993). Therapists and the clinical use of forgiveness. American Journal of Family Therapy, 21(2), 175-184.

Enright, R. D. (1996). Counseling within the forgiveness triad: On forgiving, receiving forgiveness, and self-forgiveness. Counseling and Values, 40(2), 107-126.

Enright, R. D., \& Coyle, C. T. (1998). Researching the process model of forgiveness within psychological interventions. In E. L. Worthington (Ed.), Dimensions of forgiveness (pp. 139-161). Radnor, PA: Templeton Foundation Press.

Enright, R. D., \& Fitzgibbons, R. P. (2000). Helping clients forgive: An empirical guide for resolving anger and restoring hope. Washington, DC: American Psychological Association.

Enright, R. D., Freedman, S., \& Rique, J. (1998). The psychology of interpersonal forgiveness. In R. D. Enright \& J. North (Eds.), Exploring forgiveness (pp. 46-62). Madison: University of Wisconsin Press.

Enright, R. D., Gassin, E. A., \& Wu, C. (1992). Forgiveness: A developmental view. Journal of Moral Education, 21(2), 99-114.

Exline, J. J., \& Baumeister, R. F. (2000). Expressing forgiveness and repentance: Benefits and barriers. In M. McCullough, K. Pargament, \& C. Thoresen (Eds.), Forgiveness: Theory, research, and practice (pp. 133155). New York: Guilford Press.

Fenell, D. (1993). Characteristics of long-term first marriages. Journal of Mental Health Counseling, 15, 446-460.

Fincham, F. D. (2000). The kiss of the porcupines: From attributing responsibility to forgiving. Personal Relationships, 7(1), 1-23.

Fincham, F. D. (2001). Attributions and close relationships: From balkanization to integration. In G. J. Fletcher \& M. Clark (Eds.), Blackwell handbook of social psychology (pp. 3-31). Oxford, England: Blackwell.

Fincham, F. D., \& Beach, S. R. H. (1999). Marital conflict: Implications for working with couples. Annual Review of Psychology, 50(1), 47-77.

Fincham, F. D., \& Beach, S. R. H. (2002). Forgiveness in marriage: Implications for psychological aggression and constructive communication. Personal Relationships, 9, 239-251.

Fincham, F. D., \& Beach, S. R. H. (2006). Relationship satisfaction. In D. Perlman \& A. Vangelisti (Eds.), The Cambridge Handbook of Personal Relationships (pp. 579-594). Cambridge, England: Cambridge University Press.

Fincham, F. D., Beach, S. R. H., \& Davila, J. (2004). Forgiveness and conflict resolution in marriage. Journal of Family Psychology, 18(1), $72-81$.

Fincham, F. D., Hall, J. H., \& Beach, S. R. H. (2005). 'Til lack of forgiveness doth us part: Forgiveness in marriage. In E. L. Worthington (Ed.), Handbook offorgiveness (pp. 207-226). New York: Routledge.

Fincham, F. D., Jackson, H., \& Beach, S. R. H. (2005). Transgression severity and forgiveness: Different moderators for objective and subjective severity. Journal of Social and Clinical Psychology, 24, 860-875.

Fincham, F. D., \& Kashdan, T. B. (2004). Facilitating forgiveness. In P. A. Linley \& S. Joseph (Eds.), Positive psychology in practice (pp. 617-637). Hoboken, NJ: John Wiley \& Sons.

Fincham, F. D., \& Linfield, K. J. (1997). A new look at marital quality: Can spouses feel positive and negative about their marriage? Journal of Family Psychology, 11, 489-502.

Fincham, F. D., Paleari, F., \& Regalia, C. (2002). Forgiveness in marriage: The role of relationship quality, attributions, and empathy. Personal Relationships, 9(1), 27-37.

Finkel, E. J., Rusbult, C. E., Kumashiro, M., \& Hannon, P. A. (2002). Dealing with betrayal in close relationships: Does commitment promote forgiveness? Journal of Personality and Social Psychology, 82, 956974.

Freedman, S. (2000). Creating an expanded view: How therapists can help their clients forgive. Journal of Family Psychotherapy, 11(1), 87-92.

Gandhi, M. (2000). The collected works of Mahatma Gandhi (2nd Rev. ed.). New Delhi, India: Veena Jain Publications.
Gordon, K. C., \& Baucom, D. H. (1998). Understanding betrayals in marriage: A synthesized model of forgiveness. Family Process, 37, 425-449.

Gordon, K. C., \& Baucom, D. H. (1999). A multitheoretical intervention for promoting recovery from extramarital affairs. Clinical Psychology: Science \& Practice, 6(4), 382-399.

Gordon, K. C., \& Baucom, D. H. (2003). Forgiveness and marriage: Preliminary support for a measure based on a model of recovery from a marital betrayal. American Journal of Family Therapy, 31(3), 179-199.

Gordon, K. C., Baucom, D. H., \& Snyder, D. K. (2000). The use of forgiveness in marital therapy. In M. McCullough, K. Pargament, \& C. Thoresen (Eds.), Forgiveness: Theory, research, and practice (pp. 203227). New York: Guilford Press.

Gordon, K. C., Baucom, D. H., \& Snyder, D. K. (2004). An integrative intervention for promoting recovery from extramarital affairs. Journal of Marital and Family Therapy, 30, 213-231.

Gordon, K., Baucom, D. H., \& Snyder, D. K. (2005). Forgiveness in couples: Divorce, infidelity, and couples therapy. In E. L. Worthington (Ed.), Handbook of forgiveness (pp. 407-422). New York: Routledge.

Hall, J. H., \& Fincham, F. D. (2005). Self-forgiveness: The stepchild of forgiveness research. Journal of Social and Clinical Psychology, 24, 621-637.

Hall, J. H., \& Fincham, F. D. (2006). Relationship dissolution following infidelity: The roles of attributions and forgiveness. Journal of Social and Clinical Psychology, 25(5), 508-522.

Hargrave, T. D. (1994). Families and forgiveness: A theoretical and therapeutic framework. The Family Journal, 2, 339-348.

Hargrave, T. D., \& Sells, J. N. (1997). The development of a forgiveness scale. Journal of Marital and Family Therapy, 23(1), 41-63.

Harris, A. H. S., \& Thoresen, C. E. (2005). Forgiveness, unforgiveness, health and disease. In E. L. Worthington (Ed.), Handbook of forgiveness (pp. 321-334). New York: Routledge.

Heider, F. (1958). The psychology of interpersonal relations. New York: Wiley.

James, W. (1890). The principles of psychology. New York: Holt.

Jenkins, K. W. (1992). Religion and families. In S. J. Bahr (Ed.), Family research: A sixty-year review, 1930-1990 (Vol. 2, pp. 235-288). New York: Lexington Books.

Kachadourian, L. K., Fincham, F., \& Davila, J. (2004). The tendency to forgive in dating and married couples: The role of attachment and relationship satisfaction. Personal Relationships, 11, 373-393.

Kachadourian, L. K., Fincham, F., \& Davila, J. (2005). Attitudinal ambivalence, rumination, and forgiveness of partner transgressions in marriage. Personality and Social Psychology Bulletin, 31, 334-342.

Karremans, J. C., Van Lange, P. A., Ouwerkerk, J. W., \& Kluwer, E. S. (2003). When forgiving enhances psychological well-being: The role of interpersonal commitment. Journal of Personality and Social Psychology, 84, 1011-1026.

Kearns, J. N., \& Fincham, F. D. (2004). A prototype analysis of forgiveness. Personality and Social Psychology Bulletin, 30, 838-855.

Kearns, J. N., \& Fincham, F. D. (2005). Victim and perpetrator accounts of interpersonal transgressions: Self-serving or relationship-serving biases? Personality and Social Psychology Bulletin, 31, 321-333.

Kelley, D. L. (1998). The communication of forgiveness. Communication Studies, 49(3), 1-17.

Mahoney, A., Pargament, K. I., Jewell, T., Swank, A. B., Scott, E., Emery, E., et al. (1999). Marriage and the spiritual realm: The role of proximal and distal religious constructs in marital functioning. Journal of Family Psychology, 13, 321-338.

Mahoney, A., Rye, M. S., \& Pargament, K. I. (2005). When the sacred is violated: Desecration as a unique challenge to forgiveness. In E. L. Worthington (Ed.), Handbook of forgiveness (pp. 57-72). New York: Routledge.

Malcolm, W. M., \& Greenberg, L. S. (2000). Forgiveness as a process of change in individual psychotherapy. In M. E. McCullough, K. Pargament, \& C. Thoreson (Eds.), Forgiveness: Theory, research, and practice (pp. 179-202). New York: Guilford Press.

McCullough, M., Rachal, K., Sandage, S., Worthington, E., Brown, S., \& Hight, T. (1998). Interpersonal forgiving in close relationships: II. Theoretical elaboration and measurement. Journal of Personality and Social Psychology, 75, 1586-1603.

McCullough, M., \& Root, L. M. (2005). Forgiveness as change. In E. L. Worthington (Ed.), Handbook of forgiveness (pp. 91-108). New York: Routledge. 
McCullough, M., Worthington, E., \& Rachal, K. (1997). Interpersonal forgiving in close relationships. Journal of Personality and Social Psychology, 73, 321-336.

McCullough, M. E., Fincham, F. D., \& Tsang, J. (2003). Forgiveness, forbearance, and time: The temporal unfolding of transgression-related interpersonal motivations. Journal of Personality and Social Psychology, 84, 540-557.

McCullough, M. E., Pargament, K. I., \& Thoresen, C. E. (2000). The psychology of forgiveness: History, conceptual issues, and overview. In M. McCullough, K. Pargament, \& C. Thoresen (Eds.), Forgiveness: Theory, research, and practice (pp. 1-14). New York: Guilford Press.

McCullough, M. E., \& Worthington, E. L. (1994). Models of interpersonal forgiveness and their applications to counseling: Review and critique. Counseling and Values, 39(1), 2-14.

Miller, W. R., \& Rollnick, S. (2002). Motivational interviewing: Preparing people for change (2nd ed.). New York: Guilford Press.

Obuchi, K., Kameda, M., \& Agarie, N. (1989). Apology as aggression control: Its role in mediating appraisal and response to harm. Journal of Personality and Social Psychology, 56, 219-227.

Paleari, F., Regalia, C., \& Fincham, F. (2003). Marital quality, forgiveness, empathy, and rumination: A longitudinal analysis. Personality and Social Psychology Bulletin, 31, 368-378.

Pargament, K. I. (1997). The psychology of religion and coping: Theory, research, practice. New York: Guilford Press.

Pargament, K. I., McCullough, M. E., \& Thoresen, C. E. (2000). The frontier of forgiveness: Seven directions for psychological study and practice. In M. McCullough, K. Pargament, \& C. Thoresen (Eds.), Forgiveness: Theory, research, and practice (pp. 299-319). New York: Guilford Press.

Pollard, M. W., Anderson, R. A., Anderson, W. T., \& Jennings, G. (1998). The development of a family forgiveness scale. Journal of Family Therapy, 20(1), 95-110.

Ripley, J. S., \& Worthington, E. L., Jr. (2002). Hope-focused and forgiveness-based group interventions to promote marital enrichment. Journal of Counseling and Development, 80, 452-463.

Rye, M. S., \& Pargament, K. I. (2002). Forgiveness and romantic relationships in college: Can it heal the wounded heart? Journal of Clinical Psychology, 58, 419-441.

Rye, M. S., Pargament, K. I., Ali, M., Beck, G. L., Dorff, E. N., Hallisey, C., et al. (2000). Religious perspectives on forgiveness. In M. McCullough, K. Pargament, \& C. Thoresen (Eds.), Forgiveness: Theory, research, and practice (pp. 17-40). New York: Guilford Press.
Sells, J. N., Giordano, F. G., \& King, L. (2002). A pilot study in marital group therapy. Family Journal-Counseling \& Therapy for Couples \& Families, 10(2), 156-166.

Shiffrin, R. M., \& Schneider, W. (1977). Controlled and automatic human information processing: II. Perceptual learning, automatic attending, and a general theory. Psychological Review, 84(2), 127-190.

Stanley, S. M., Markman, H. J., \& Blumberg, S. L. (2001). Prevention and Relationship Enhancement Program: Leader's Manual. Greenwood Village, CO: PREP.

Stillwell, A. M., \& Baumeister, R. F. (1997). The construction of victim and perpetrator memories: Accuracy and distortion in role-based accounts. Personality and Social Psychology Bulletin, 23, 1157-1172.

Toussaint, L. L., Williams, D. R., Musick, M. A., \& Everson, S. A. (2001). Forgiveness and health: Age differences in a U.S. probability sample. Journal of Adult Development, 8, 249-257.

Tsang, J., McCullough, M., \& Fincham, F. D. (2006). Forgiveness and the psychological dimension of reconciliation: A longitudinal analysis. Journal of Social and Clinical Psychology, 25(4), 404-428.

Vaughan, L. A. (2001). The relationship between marital satisfaction levels associated with participation in the free (forgiveness and reconciliation through experiencing empathy) and hope-focused marital enrichment program. Dissertation Abstracts International, 62(1124), 2-B.

Weiner, B., Graham, S., Peter, O., \& Zmuidinas, M. (1991). Public confession and forgiveness. Journal of Personality, 59, 281-312.

Worthington, E. L. (1994). Marriage counseling: A Christian approach. Journal of Psychology and Christianity, 13(2), 166-173.

Worthington, E. L. (1998). An empathy-humility-commitment model of forgiveness applied within family dyads. Journal of Family Therapy, 20(1), 59-76.

Worthington, E. L. (2001). Unforgiveness, forgiveness, and reconciliation and their implications for societal interventions. In R. G. Helmick \& R. L. Petersen (Eds.), Forgiveness and reconciliation: Religion, public policy, and conflict transformation (pp. 161-182). Philadelphia: Templeton Foundation Press.

Worthington, E. L. (2005). More questions about forgiveness: Research agenda for 2005-2015. In E. L. Worthington (Ed.), Handbook of forgiveness (pp. 557-575). New York: Routledge.

Worthington, E. L., \& DiBlasio, F. (1990). Promoting mutual forgiveness within the fractured relationship. Psychotherapy: Theory, Research, Practice, Training, 27, 219-223.

Younger, J. W., Piferi, R. L., Jobe, R. L., \& Lawler, K. A. (2004). Dimensions of forgiveness: The views of laypersons. Journal of Social and Personal Relationships, 21, 837-855. 